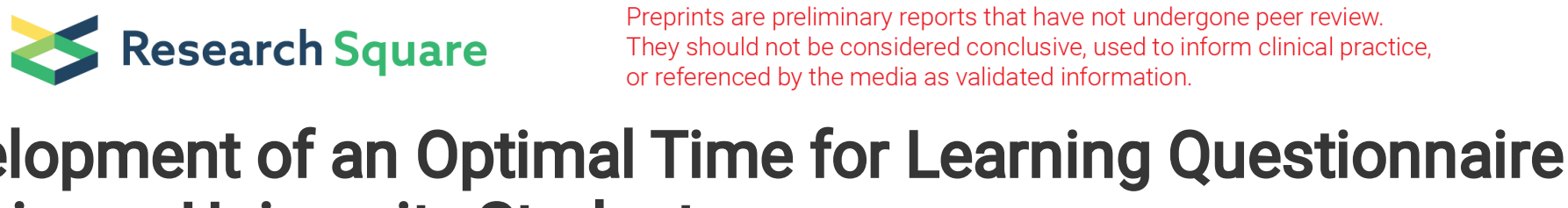 Development of an Optimal Tim
in Chinese University Students
}

\author{
Lingshan LIU \\ Zhejiang University College of Medicine \\ Hongyuan LV \\ Zhejiang University College of Medicine \\ Yifan LU \\ Zhejiang University College of Medicine

\section{Chu WANG} \\ Zhejiang Chinese Medical University

\section{Hao CHAl} \\ Zhejiang University of Technology

\section{Lars M. RIMOL} \\ Norwegian University of Science and Technology \\ Wei Wang ( $\nabla$ wew@ntnu.no) \\ Zhejiang University College of Medicine
}

\section{Research Article}

Keywords: Confirmatory factor analysis, Optimum time for learning, Principal component analysis, Structure-validated questionnaire

Posted Date: February 11th, 2022

DOI: https://doi.org/10.21203/rs.3.rs-1321049/v1

License: (c) (i) This work is licensed under a Creative Commons Attribution 4.0 International License. Read Full License 


\section{Abstract \\ Background}

Autonomous learning is crucial for students' academic achievements, however, there lacks a structure-validated questionnaire to measure the optimal time for autonomous learning with different learning contents.

\section{Methods}

Based on the previous investigations, we have designed a matrix of 49 items based on seven learning contents and seven time periods of a day to measure the optimal time for autonomous learning and invited 305 Chinese university students to answer the matrix.

\section{Results}

Through both exploratory and confirmatory factor analyses, we have developed an Optimal Time for Learning Questionnaire with a satisfactory model structure of five factors $(7,6,6,6,5$ items per factor respectively) namely Noon, Late Night, Nightfall, Morning and Afternoon. The internal reliabilities of these factors were acceptable, and their intercorrelations were significant, albeit in low or medium levels.

\section{Conclusions}

The Optimal time for Learning Questionnaire may help students find their optimal learning efficiency individually.

\section{Introduction}

Autonomous learning, also named self-managed learning (Lizzio \& Wilson, 2005), self-regulated learning (Boekaerts \& Niemivirta, 2000; Entwistle \& McCune, 2004), or self-directed learning (Garrison, 1997), denotes a process where students possess sufficient opportunity to organize and regulate their own learning. In autonomous learning, students' learning efficiency may vary with the learning contents (or concepts) and time epochs during a day. Previous studies have suggested that there exists a time-of-day effect in one's learning efficiency. For example, young participants showed superior memory accuracy in the afternoon compared to that in the morning (Hourihan \& Benjamin, 2014). When identified as morning type or evening type, students reported differences in memory, interest, motivation, and achievement across time of day (Anderson et al., 1991; Itzek-Greulich et al., 2016). In the field of logical reasoning, students' speed and performance improved markedly from morning to noon, and subsequently performance fell off rapidly from afternoon to night (Folkard, 1975).

Several other factors influence cognitive performance and thus contribute to intra-individual variance in learning efficiency. Most importantly, the circadian rhythms in cognitive processes affect school related activities such as attention and memory (Valdez, 2019). Circadian rhythms have been found in three basic cognitive processes which are interconnected with each other: attention, working memory and executive functions. Attention denotes to the act of selectively concentrating on a discrete aspect of information while ignoring other perceivable information, which also interacts effectively with the environment (Nobre \& Kastner, 2014); working memory comprises the storage, retrieval, and use of information (Baddeley \& Hitch, 1974); and executive functions refer to the ability to program or regulate behavior, which is essential for problem solving, decision making as well as self-control (Lezak et al., 2012). These cognitive processes roughly reach their lowest levels during nighttime and early morning, improve around noon, and are at even 
higher levels during afternoon and in the evening (Valdez et al., 2005; Ramírez et al., 2006; García et al., 2012; Gallegos et al., 2019), demonstrating their coordination with the physiological rhythms of the human body (Valdez, 2019).

The learning efficiency and time course of cognitive performance are nonetheless also modulated by other conditions. The "chronotype" is a reproducible and stable trait of individuals, which encompasses morning type, evening type and intermediate type according to preferred time of learning or other activities (Kantermann \& Eastman, 2018). The morning and evening types show an advance or a delay in cognitive rhythms respectively (Roenneberg et al., 2003). Hunger and sleep deprivation influence the rhythms of cognitive performance as well (Benau et al., 2014; Killgore \& Weber, 2014), leading to the impairment of attention, memory and executive functions (Benton \& Parker, 1998; Doniger et al., 2006; Krause et al., 2017). The fluctuations of attention interrelate with emotion (Taylor \& Fragopanagos, 2005), and certain emotional states appear to facilitate memory control (Engen \& Anderson, 2018) and decision making (Woodcock et al, 2020). Finally, exposure to environmental noise deteriorates cognitive performance with regard to comprehension, memory, attention, as well as executive functions (Clark \& Paunovic, 2018).

A classical theory of learning skills is the "Building Blocks of Learning" (Goldstein \& Mather, 1998). Learning skills are regarded as comprising ten building blocks that reflect foundational skills, symbolic or perceptual processing skills, and conceptual or thinking skills, including attention and self-regulation, emotion, behavior, self-esteem, phonological processing, orthographical processing, motor processing, thinking with language, thinking with images, and thinking with strategies (Abu-Hamour, 2014; Goldstein \& Mather, 1998). In the current study, we would separate the learning contents into seven elements, i.e., language learning, problem analyzing, memorizing, comprehension, logic thinking, drawing and writing.

There are several inventories that have been developed to assess learning efficiency and learning style (Horne \& Östberg, 1976; Fleming \& Mills, 1992; Duff, 2004; Fleming, 2001; Roenneberg et al., 2003). To date however, there is no single study which illustrates a structure-validated questionnaire that investigates the optimal time for autonomous learning of different leaning-contents. There is no standard division of time epoch of a day either. Some scholars preferred to use the exact scales of time epoch (e.g., 04:00-07:00 AM or 8:00-11:00 PM) when measuring the rhythms of cognitive performance (Garcia et al., 2012; Ramirez et al., 2006; Valdez et al., 2005). However, cognitive performance and learning efficiency fluctuate with numerous factors within different individuals (Benau et al., 2014; Roenneberg et al., 2003; Taylor \& Fragopanagos, 2005), and the exact time points may not be suitable for all participants when referring to the automatic learning.

In the current study, we adopted both exploratory and confirmatory factor analyses in order to validate the structure of a questionnaire. Furthermore, we roughly divided the day into the early morning, morning, noon, afternoon, nightfall, evening, and the late night. On the other hand, based on previous studies, the optimal time of learning refers to the time epoch when an individual is highly focused, does not easily fatigue, stable in mood, fluent in thinking, and with the highest learning efficiency. Thus, we recruited a group of university students to answer a matrix of statements regarding the optimal time for autonomous learning. Considering that different cognitive performances show similar rhythms in a day (Valdez, 2019), we hypothesized that the efficiency of autonomous learning is primarily affected by the time of day instead of the learning contents.

\section{Methods}

\section{Participants}

Altogether 305 students (116 men, mean age: 21.39 years \pm 1.94 S.D., range: $19-28$ years; and 189 women, mean age: $21.31 \pm 1.85$, range:18-26) were recruited in the current study. The participants were enrolled in the Zhejiang University (Hangzhou, China), a typical comprehensive Chinese university with a large student population. They were all of Han 
ethnicity and majored in Modern Medicine, Science, Engineering, Management, Agronomy, History, Sociology, Literature, and Philosophy. There was no significant age difference between the male and female participants $(t=.35, p=.728,95 \%$ Confidence Interval $=-.36 \sim$.52). All participants were free from any somatic or psychiatric illnesses, had not experienced stressful life-events recently, and were medication or alcohol free at least $72 \mathrm{~h}$ prior to testing. The study protocol was approved by the Ethic Committee of the School of Public Health, Zhejiang University and all participants had given their written informed consents.

\section{Measures}

Participants were asked to respond to a matrix of 49 items regarding the optimal time for autonomous learning in a quiet room. They were asked to use a five-point Likert rating scale: 1-very unlike me, 2-moderately unlike me, 3-somewhat like and unlike me, 4-moderately like me, and 5-very like me. The matrix concerned following aspects (seven items each based on time periods below): 1) the optimal time for language learning, 2) the optimal time for analyzing a problem, 3) the optimal time for memorizing, 4) the optimal time for comprehension, 5) the optimal time for logical thinking, 6) the optimal time for drawing, and 7) the optimal time for writing. The participants were asked to choose between the following time periods: 1) early morning (between getting up and breakfast), 2) morning, 3) noon (between lunch and midday rest), 4) afternoon, 5) nightfall (around dinner), 6) evening, and 7) late night. The presentation of the items was randomized in the matrix.

\section{Statistical Analyses}

Responses to the 49 items were subjected to principal component analysis using the Predictive Analytics Software Statistics, Release Version 18.0 (SPSS Inc., 2009, Chicago, IL). The factor loadings were rotated orthogonally through the varimax normalized methods. Items which loaded less heavily (below .50) on a target factor, or cross-loaded heavily (above .25) on more than one factors were removed from subsequent analyses one-by-one. The procedure continued until no further item was needed to be removed. Then, the fit of the remaining data (i.e., components extracted as latent factors) were assessed by confirmatory factor analysis via the structural equation modeling software Analysis of Moment Structures (AMOS), version 17.0 (Arbuckle, AMOS Development Corp. 2008, Crawfordville, FL). The following indices were used to identify the model fit: the $\chi^{2} / \mathrm{df}$, the goodness of fit index, the adjusted goodness of fit index, the comparative fit index, the Tucker-Lewis Index, and the root mean square error of approximation (Bentler \& Bonett, 1980; Bentler, 1990; Browne \& Cudeck, 1993).

When factors and their related items had been identified, the factor scores of each gender group and the internal reliabilities (the Coefficient $\mathrm{H}$ ) were then calculated in all participants. The gender difference of each factor scores was evaluated by two-way ANOVA (i.e., gender $\times$ factor score) plus the post-hoc Student $t$ test. A p value below .05 was considered significant. Moreover, the Pearson correlation test was used to search for possible relationships within the factors, with a p value below .01 was considered significant.

\section{Results}

Responses to the 49 items measuring the optimal time for autonomous learning were first submitted to a principal component analysis. Results of the pre-analysis check were acceptable (KMO = .84; the Bartlett test of sphericity = 7099.99; $p$.001). The analysis disclosed 11 factors with eigenvalues greater than 1.0 , and the scree plot indicated a level-off from the sixth factor on. The eigenvalues of the first five factors were 7.50, 7.27, 3.25, 2.85 and 2.42 respectively, which altogether accounted for $47.50 \%$ of the total variance (the first four factors altogether accounted for $42.57 \%$ ). After the varimax normalized rotation, in the six-factor model, there were no validly consistent items in the sixth factor. Therefore, a five-factor model was chosen for the confirmatory factor analysis. 
Three AMOS fit-models of five-factors with different items were constructed (Table 1) and the 30-item model $(7,6,6,6,5$ items respectively for the five factors) was the best among the models. The standardized factor correlations for the 30 item model structure were also acceptable (Figure 1). Based on these 30 items, we developed an Optimal Time for Learning Questionnaire (OTL, Table 2), and used it in the subsequent analyses.

Table 1

Five-factor fitting models of the Optimum Time for Learning Questionnaire in 305 participants.

\begin{tabular}{|lllllllll|}
\hline $\begin{array}{l}\text { Total } \\
\text { item } \\
\text { number }\end{array}$ & $\begin{array}{l}\text { Item } \\
\text { numbers } \\
\text { each } \\
\text { factor }\end{array}$ & X2/df & $\begin{array}{l}\text { Goodness } \\
\text { of fit } \\
\text { index }\end{array}$ & $\begin{array}{l}\text { Adjusted } \\
\text { goodness } \\
\text { of fit } \\
\text { index }\end{array}$ & $\begin{array}{l}\text { Tucker- } \\
\text { Lewis } \\
\text { index }\end{array}$ & $\begin{array}{l}\text { Comparative } \\
\text { fit index }\end{array}$ & $\begin{array}{l}\text { Root mean } \\
\text { square error of } \\
\text { approximation }\end{array}$ & $\begin{array}{l}\text { Standardized } \\
\text { Root Mean } \\
\text { Square } \\
\text { Residual }\end{array}$ \\
\hline 38 & $\begin{array}{l}12,8,7, \\
6,5\end{array}$ & 2.56 & .75 & .72 & .77 & .78 & .07 & .072 \\
\hline 34 & $\begin{array}{l}8,8,7,6, \\
5\end{array}$ & 2.51 & .78 & .75 & .79 & .81 & .07 & .070 \\
\hline 30 & $7,6,6,6$, & 2.11 & .84 & .81 & .85 & .87 & .06 & .064 \\
\hline 5
\end{tabular}


Table 2

Item-factor loadings in 305 participants.

\begin{tabular}{|c|c|c|c|c|c|}
\hline Item (My optimal time of...) & Factor 1 & 2 & 3 & 4 & 5 \\
\hline Comprehension is noon. & .77 & .02 & .17 & .11 & .08 \\
\hline Problem analyzing is noon. & .74 & -.03 & .10 & .12 & .18 \\
\hline Language learning is noon. & .70 & .01 & .10 & .08 & .08 \\
\hline Memorizing is noon. & .70 & .03 & .06 & -.04 & .07 \\
\hline Logic thinking is noon. & .69 & .06 & .04 & .04 & .12 \\
\hline Drawing is noon. & .67 & .05 & .09 & .24 & .14 \\
\hline Writing is noon. & .62 & .06 & .18 & .07 & .01 \\
\hline Comprehension is late night. & .17 & .82 & .08 & -.07 & -.10 \\
\hline Problem analyzing is late night. & .13 & .82 & .01 & -.11 & -.06 \\
\hline Logic thinking is late night. & .10 & .81 & .10 & -.02 & -.07 \\
\hline Memorizing is late night. & .12 & .70 & .04 & -.14 & .09 \\
\hline Problem analyzing is evening. & -.23 & .66 & .21 & -.08 & .07 \\
\hline Writing is late night. & -.11 & .61 & .16 & .10 & .11 \\
\hline Comprehension is nightfall. & .11 & .07 & .77 & .03 & .06 \\
\hline Problem analyzing is nightfall & .03 & .14 & .75 & -.03 & .16 \\
\hline Logic thinking is nightfall. & .13 & .16 & .71 & -.01 & .11 \\
\hline Drawing is nightfall. & .11 & .08 & .71 & -.03 & .18 \\
\hline Writing is nightfall. & .10 & -.01 & .68 & .06 & -.09 \\
\hline Memorizing is nightfall. & .24 & .14 & .62 & -.14 & .04 \\
\hline Language learning is morning. & -.04 & -.04 & -.05 & .80 & .10 \\
\hline Language learning is early morning. & .14 & -.06 & .11 & .73 & -.09 \\
\hline Logic thinking is morning. & .08 & -.01 & -.09 & .69 & .16 \\
\hline Memorizing is morning. & .02 & -.22 & -.08 & .68 & .02 \\
\hline Memorizing is early morning. & .16 & -.06 & .09 & .68 & -.15 \\
\hline Drawing is morning. & .20 & .11 & -.08 & .51 & .23 \\
\hline Problem analyzing is afternoon. & .02 & .03 & .11 & .12 & .76 \\
\hline Logic thinking is afternoon. & .08 & -.02 & .08 & .11 & .75 \\
\hline Memorizing is afternoon. & .25 & .02 & .04 & -.11 & .75 \\
\hline Language learning is afternoon. & .25 & .09 & -.01 & -.11 & .63 \\
\hline Comprehension is afternoon. & .06 & -.08 & .18 & .15 & .61 \\
\hline
\end{tabular}


Factor 1 was called "Noon", which described the time between lunch and midday rest and was applicable to all the seven learning contents. Factor 2 was called "Late Night", which represented the dead of night and was applicable to all learning contents except for language learning and drawing. Factor 3 was called "Nightfall", which reflected the time around dinner. This factor was applicable to the other six learning contents excluding language learning. Factor 4 was called "Morning", which comprised the time between getting up and lunch. The learning contents in Factor 4 consisted of language learning, logical thinking, memorizing, and drawing. Factor 5 was called "Afternoon", which referred to the time between lunch and dinner and includes five learning contents, other than drawing and writing.

There was no significant difference in the OTL factor scores between two gender groups $(F[1,303]=.47, p=.495$, mean squared effect $=17.44)$. The internal reliabilities of OTL five factors were all above .80 , and their inter-correlations were significant but remained on a low or medium level (Table 3).

Table 3

Scale scores (means \pm S.D.) of the Optimum Time for Learning Questionnaire in men $(n=116)$ and women $(n=189)$, and their internal reliabilities (Coefficient $\mathrm{H}$ ) and inter-correlations.

\begin{tabular}{|c|c|c|c|c|c|c|c|c|}
\hline \multirow[t]{2}{*}{ Factor } & \multicolumn{3}{|c|}{ Factor scores } & \multirow{2}{*}{$\begin{array}{l}\text { Coefficient } \\
\mathrm{H}\end{array}$} & \multicolumn{4}{|c|}{ Inter-correlation } \\
\hline & Male & Female & $\begin{array}{l}\text { 95\% Confidence } \\
\text { Interval }\end{array}$ & & $\begin{array}{l}\text { Factor } \\
1\end{array}$ & 2 & 3 & 4 \\
\hline Factor 1 (Noon) & $\begin{array}{l}14.78 \pm \\
5.37\end{array}$ & $\begin{array}{l}14.71 \pm \\
4.77\end{array}$ & $-1.09 \sim 1.24$ & .88 & & & & \\
\hline $\begin{array}{l}\text { Factor } 2 \text { (Late } \\
\text { Night) }\end{array}$ & $\begin{array}{l}20.47 \pm \\
5.52\end{array}$ & $\begin{array}{l}19.77 \pm \\
5.67\end{array}$ & $-.60 \sim 2.00$ & .89 & .10 & & & \\
\hline $\begin{array}{l}\text { Factor } 3 \\
\text { (Nightfall) }\end{array}$ & $\begin{array}{l}17.63 \pm \\
5.13\end{array}$ & $\begin{array}{l}17.94 \pm \\
4.93\end{array}$ & $-1.48 \sim .85$ & .86 & $.30 \star$ & $.26^{\star}$ & & \\
\hline $\begin{array}{l}\text { Factor } 4 \\
\text { (Morning) }\end{array}$ & $\begin{array}{l}17.69 \pm \\
5.19\end{array}$ & $\begin{array}{l}18.80 \pm \\
5.20\end{array}$ & $-2.32 \sim .09$ & .86 & $.23^{*}$ & -.14 & -.02 & \\
\hline $\begin{array}{l}\text { Factor } 5 \\
\text { (Afternoon) }\end{array}$ & $\begin{array}{l}14.85 \pm \\
3.80\end{array}$ & $\begin{array}{l}15.30 \pm \\
3.65\end{array}$ & $-1.31 \sim .41$ & .84 & $.32^{\star}$ & .04 & $.23^{\star}$ & .11 \\
\hline
\end{tabular}

\section{Discussion}

Using both exploratory and confirmatory factor analysis on 49 items regarding optimal time for autonomous learning, we have constructed a satisfactory model structure of 30 items with five scales, namely Noon, Late Night, Nightfall, Morning and Afternoon. These scales had acceptable internal reliabilities and low or medium inter-correlations, which confirmed our hypothesis that the efficiency of autonomous learning was mainly affected by time epoch of day. Although we have included various learning contents, the distribution of OTL items was primarily based on time of day, indicating that the time effect was most prominent in one's learning efficiency. Our results are consistent with the idea of circadian rhythms of cognitive performance, in that the different aspects such as memory, comprehension, logical thinking and language learning followed similar pattens of cognitive rhythm, i.e., with higher level during daytime hours and lower during nighttime and early in the morning. This maintains a phasic relationship to body temperature (Valdez et al., 2019).

Factor 1 (Noon) and Factor 3 (Nightfall) are linked with the times of eating, and thus are closely related with food and diet. Some people prefer to study around eating time since a healthy dietary pattern and adequate nutrition are necessary to optimize brain function and prevent cognitive decline (Marie-Noël et al., 2009). Meanwhile, cognitive capacity could be influenced by components of diet, such as fish, fruits, vegetables, nuts, and seeds help to prevent cognitive deterioration, while those rich in added sugars and saturated fat are associated with the impairment of cognitive function (Martinez 
Garcia et al., 2018; Tucker, 2016). Particularly, the Mediterranean diet, characterized by using olive oil as the main culinary fat, being high in plant-based foods, moderate in fish, seafood and red wine, and low in meat, butter or other dairy products, has been suggested to improve cognition and protect against decline (Martínez-Lapiscina et al., 2013; Petersson \& Philippou, 2016). Moreover, food intake also regulates the release of neurotransmitters (Briguglio et al., 2018). For instance, sufficient dopamine contributes to the improvement of cognitive capacity, and promotes attention, insight and problem solving (Nieoullon, 2002; Volkow et al., 2011; Zhang \& Zhang, 2016) and low levels of serotonin has been linked with deterioration in learning, reasoning and memory (Martinez Garcia et al., 2018).

Factor 4 (Morning) and Factor 5 (Afternoon) are correlated with diet as well, but the effect of sleep or rest also appears in these factors, as these periods take place immediately after a period of sleep. Previous studies have suggested that sleep plays a crucial role in memory stabilization and integration, and functions as a brain state optimizing memory consolidation (Cousins \& Fernández, 2019; Rasch \& Born, 2013). Sleep deprivation impairs brain functions and the cognitive performance in the field of attention and work memory especially in the capacity to encode new information (Killgore \& Weber, 2014; Krause et al., 2017). Indeed, Wild et al. (2018) reported that sleeping more than usual the night before testing was associated with better performance, suggesting even a single night's sleep can benefit in learning. Actually, the habit of siesta is prevalent in the Chinese population (Kang et al., 2017). The Factor 5 (Afternoon) of our study might also be explained by the effect of sleep or rest owing to the noon break in study schedule when students could take a nap or get some rest.

Factor 2 (Late Night) refers to the silence of night with a peaceful atmosphere, which is often connected with the calmful of the surrounding physical-environment. The optimal learning efficiency of different task types have been identified under environmental interactions. One study has shown that although the comfortable ambient-temperatures were varied, participants involved in perception, memory, problem-solving and attention tasks performed best under relatively/ fairly quiet and bright or moderately light surroundings (Xiong et al., 2018), suggesting that quiet environment helps to enhance the cognitive performance. Moreover, healthy environment might be related with emotional stability, which benefits the ability of memory control (Engen \& Anderson, 2018) and decision making (Woodcock et al, 2020). On the contrary, exposure to noise has a terrible impact on the ability of perception, comprehension, memory as well as writing (Klatte et al., 2013).

Our study also suffered from several design limitations. Firstly, although we recruited students from different academic majors, the participants were mainly undergraduates of clinical medicine, so whether the results can be generalized to other majors or grades needs further research. Secondly, we did not record the chronotypes of the participants. Chronotypes have a nonnegligible impact on the circadian rhythms in cognitive performance (Goldstein et al., 2007). Thirdly, recall bias may have influenced our measurements of optimal learning time for different contents. Fourthly, our study was exclusively conducted in China, where noon-time nap is common, which may negatively affect the generalizability of the present findings. Fifthly, we did not record the nutritional habits of the participants, which may have influenced their responses to the questionnaire, since comfortable diets are fuels for optimal level of cognition. Nevertheless, using both exploratory and confirmatory factor analyses in Chinese university students, we have developed a structure-validated scale of optimal learning time, which might help students of different specialties to optimize their everyday training efficiency.

\section{Declarations}

\section{Acknowledgements}

The authors thank all participants of the study for providing precious data regarding their optimal time for learning.

\section{Funding}


This work was not supported by any funding.

\section{Author Contributions}

WW conceived the study, $L L$ and $H L$ contributed to the study design, $L L, H L, Y L, C W, H C$, and LR collected, analyzed and interpreted the data, and $L L, H L$, and WW drafted the paper. LL and HL contributed equally to the work described in the present paper. All authors read and approved the final manuscript.

Ethics approval and consent to participate: The current study design was approved by the Ethic Committee of the School of Public Health, Zhejiang University. Participants gave their written informed consent to participate in the current study.

Consent for publication: All authors have read and approved the final version of the manuscript.

Availability of data and materials: The datasets generated and/or analysed during the current study are available in the repository of the Department of Psychiatry and Clinical Psychology/ School of Public Health, Zhejiang University.

Competing interests: None to declare.

Others: Regarding research work described in the paper, each one of our co-authors, LL, HL, YL, CW, HC, LR, and WW, declares that there is no conflict of interest, and conforms to the Helsinki Declaration concerning human rights and informed consent, and follows correct procedures concerning treatment of humans in research.

\section{References}

1. Abu-Hamour, B. (2014). Students with learning disabilities and challenging behaviors in Jordan. International Education Studies, 7(4), 98-109.

2. Anderson, M. J., Petros, T. V., Beckwith, B. E., Mitchell, W. W., \& Fritz, S. (1991). Individual differences in the effect of time of day on long-term memory access. The American Journal of Psychology, 104(2), 241-255

3. Baddeley, A. D., \& Hitch, G. (1974). Working memory. In G. H. Bower (Ed.), Psychology of Learning and Motivation (Vol. 8, pp. 47-89). New York: Academic press.

4. Benau, E. M., Orloff, N. C., Janke, E. A., Serpell, L., \& Timko, C. A. (2014). A systematic review of the effects of experimental fasting on cognition. Appetite, 77, 52-61.

5. Bentler, P. M. (1990). Comparative fit indexes in structural models. Psychological Bulletin, 107(2), 238.

6. Bentler, P. M., \& Bonett, D. G. (1980). Significance tests and goodness of fit in the analysis of covariance structures. Psychological Bulletin, 88(3), 588-606.

7. Benton, D., \& Parker, P. Y. (1998). Breakfast, blood glucose, and cognition. The American Journal of Clinical Nutrition, 67(4), 772S-778S.

8. Boekaerts, M., \& Niemivirta, M. (2000). Self-regulated learning: Finding a balance between learning goals and egoprotective goals. In M. Bockaerts, P. R. Pintrich, \& M. Zcidner (Eds.), Handbook of Self-regulation (pp. 417-450). San Diego, CA: Academic Press.

9. Briguglio, M., Dell'Osso, B., Panzica, G., Malgaroli, A., Banfi, G., Zanaboni Dina, C., Galentino, R., \& Porta, M. (2018). Dietary neurotransmitters: A narrative review on current knowledge. Nutrients, 10(5), 591.

10. Browne, M. W., \& Cudeck, R. (1993). Alternative ways of assessing model fit. In Testing structural equation models. Sage Newbury Park:136-162.

11. Clark, C., \& Paunovic, K. (2018). WHO environmental noise guidelines for the European region: A systematic review on environmental noise and cognition. International Journal of Environmental Research and Public Health, 15(2), 
285.

12. Cousins, J. N., \& Fernández, G. (2019). The impact of sleep deprivation on declarative memory. Progress in Brain Research, 246, 27-53.

13. Doniger, G. M., Simon, E. S., \& Zivotofsky, A. Z. (2006). Comprehensive computerized assessment of cognitive sequelae of a complete 12-16 hour fast. Behavioral Neuroscience, 120(4), 804-816.

14. Duff, A. (2004). Approaches to learning: The revised approaches to studying inventory. Active Learning in Higher Education, 5(1), 56-72.

15. Engen, H. G., \& Anderson, M. C. (2018). Memory control: a fundamental mechanism of emotion regulation. Trends in Cognitive Sciences, 22(11), 982-995.

16. Entwistle, N., \& McCune, V. (2004). The conceptual bases of study strategy inventories. Educational Psychology Review, 16(4), 325-345.

17. Fleming, N. D. (2001). Teaching and learning styles: VARK strategies. Christchurch, New Zealand: N.D. Fleming.

18. Fleming, N. D., \& Mills, C. (1992). Not another inventory, rather a catalyst for reflection. To Improve the Academy, 11(1), 137-155.

19. Folkard, S. (1975). Diurnal variation in logical reasoning. British Journal of Psychology, 66(1), 1-8.

20. Gallegos, C., García, A., Ramírez, C., Borrani, J., Azevedo, C. V., \& Valdez, P. (2019). Circadian and homeostatic modulation of the attentional blink. Chronobiology International, 36(3), 343-352.

21. García, A., Ramírez, C., Martínez, B., \& Valdez, P. (2012). Circadian rhythms in two components of executive functions: cognitive inhibition and flexibility. Biological Rhythm Research, 43(1), 49-63.

22. Garrison, D. R. (1997). Self-directed learning: Toward a comprehensive model. Adult Education Quarterly, 48(1), 1833.

23. Goldstein, D., Hahn, C. S., Hasher, L., Wiprzycka, U. J., \& Zelazo, P. D. (2007). Time of day, intellectual performance, and behavioral problems in morning versus evening type adolescents: Is there a synchrony effect? Personality and Individual Differences, 42(3), 431-440.

24. Goldstein, S., \& Mather, N. (1998). Overcoming Underachieving: An Action Guide to Helping Your Child Succeed in School. New York: Wiley.

25. Horne, J. A., \& Östberg, O. (1976). A self-assessment questionnaire to determine morningness-eveningness in human circadian rhythms. International Journal of Chronobiology, 4(2), 97-110

26. Hourihan, K. L., \& Benjamin, A. S. (2014). State-based metacognition: How time of day affects the accuracy of metamemory. Memory, 22(5), 553-558.

27. Itzek-Greulich, H., Randler, C., \& Vollmer, C. (2016). The interaction of chronotype and time of day in a science course: Adolescent evening types learn more and are more motivated in the afternoon. Learning and Individual Differences, 51, 189-198.

28. Kang, H., Feng, X., Zhang, B., Guo, E., Wang, L., Qian, Z., Liu, P., Wen, X., Xu, W., Li, Y., Jiang, C., Wu, Z., Zhang, H., \& Liu, A. (2017). The siesta habit is associated with a decreased risk of rupture of intracranial aneurysms. Frontiers in Neurology, 8, 451-451.

29. Kantermann, T., \& Eastman, C. I. (2018). Circadian phase, circadian period and chronotype are reproducible over months. Chronobiology International, 35(2), 280-288.

30. Killgore, W. D., \& Weber, M. (2014). Sleep deprivation and cognitive performance. In M. T. Bianchi (Ed.), Sleep deprivation and disease (pp. 209-229). New York: Springer.

31. Klatte, M., Bergström, K., \& Lachmann, T. (2013). Does noise affect learning? A short review on noise effects on cognitive performance in children. Frontiers in Psychology, 4, 578.

Page 10/12 
32. Krause, A. J., Simon, E. B., Mander, B. A., Greer, S. M., Saletin, J. M., Goldstein-Piekarski, A. N., \& Walker, M. P. (2017). The sleep-deprived human brain. Nature Reviews Neuroscience, 18(7), 404-418.

33. Lezak, M. D., Howieson, D. B., Bigler, E. D., \& Tranel, D. (2012). Neuropsychological assessment. 5th ed. New York: Oxford University Press.

34. Lizzio, A., \& Wilson, K. (2005). Self-managed learning groups in higher education: Students' perceptions of process and outcomes. British Journal of Educational Psychology, 75(3), 373-390.

35. Marie-Noël Vercambre, M. N., Boutron-Ruault, M. C., Ritchie, K., Clavel-Chapelon, F., \& Berr, C. (2009). Long-term association of food and nutrient intakes with cognitive and functional decline: a 13-year follow-up study of elderly French women. British Journal of Nutrition, 102(3), 419-427.

36. Martinez Garcia, R. M., Jimenez Ortega, A. I., Lopez Sobaler, A. M., \& Ortega, R. M. (2018). Nutrition strategies that improve cognitive function. Nutricion Hospitalaria, 35(Spec No6), 16-19.

37. Martínez-Lapiscina, E. H., Clavero, P., Toledo, E., Estruch, R., Salas-Salvadó, J., San Julián, B., Sanchez-Tainta, A., Ros, E., Valls-Pedret, C., \& Martinez-Gonzalez, M. Á. (2013). Mediterranean diet improves cognition: The PREDIMEDNAVARRA randomised trial. Journal of Neurology, Neurosurgery and Psychiatry, 84(12), 1318-1325.

38. Nieoullon, A. (2002). Dopamine and the regulation of cognition and attention. Progress in Neurobiology, 67(1), 5383.

39. Nobre, K., \& Kastner, S. (2014). The Oxford handbook of attention. New York: Oxford University Press.

40. Petersson, S. D., \& Philippou, E. (2016). Mediterranean diet, cognitive function, and dementia: A systematic review of the evidence. Advances in Nutrition (Bethesda, Md.), 7(5), 889-904.

41. Ramírez, C., Talamantes, J., García, A., Morales, M., Valdez, P., \& Menna-Barreto, L. (2006). Circadian rhythms in phonological and visuospatial storage components of working memory. Biological Rhythm Research, 37(5), 433441.

42. Rasch, B., \& Born, J. (2013). About sleep's role in memory. Physiological Reviews, 93(2), 681-766.

43. Roenneberg, T., Wirz-Justice, A., \& Merrow, M. (2003). Life between clocks: daily temporal patterns of human chronotypes. Journal of Biological Rhythms, 18(1), 80-90.

44. Taylor, J. G., \& Fragopanagos, N. F. (2005). The interaction of attention and emotion. Neural Networks, 18(4), 353369.

45. Tucker, K. L. (2016). Nutrient intake, nutritional status, and cognitive function with aging. Annals of the New York Academy of Sciences, 1367(1), 38-49.

46. Valdez, P. (2019). Circadian rhythms in attention. The Yale Journal of Biology \& Medicine, 92(1), 81-92.

47. Valdez, P., Ramírez, C., García, A., Talamantes, J., Armijo, P., \& Borrani, J. (2005). Circadian rhythms in components of attention. Biological Rhythm Research, 36(1-2), 57-65.

48. Volkow, N. D., Wang, G. J., \& Baler, R. D. (2011). Reward, dopamine and the control of food intake: implications for obesity. Trends in Cognitive Sciences, 15(1), 37-46.

49. Wild, C. J., Nichols, E. S., Battista, M. E., Stojanoski, B., \& Owen, A. M. (2018). Dissociable effects of self-reported daily sleep duration on high-level cognitive abilities. Sleep, 41(12), zsy182.

50. Woodcock, K. A., Cheung, C., Marx, D. G., \& Mandy, W. (2020). Social decision making in autistic adolescents: The role of theory of mind, executive functioning and emotion regulation. Journal of Autism and Developmental Disorders, 50(7), 2501-2512.

51. Xiong, L., Huang, X., Li, J., Mao, P., Wang, X., Wang, R., \& Tang, M. (2018). Impact of indoor physical environment on learning efficiency in different types of tasks: A $3 \times 4 \times 3$ full factorial design analysis. International Journal of Environmental Research and Public Health, 15(6), 1256.

Page $11 / 12$ 
52. Zhang, S., \& Zhang, J. (2016). The association of DRD2 with insight problem solving. Frontiers in Psychology, 7, 1865-1865.

\section{Figures}

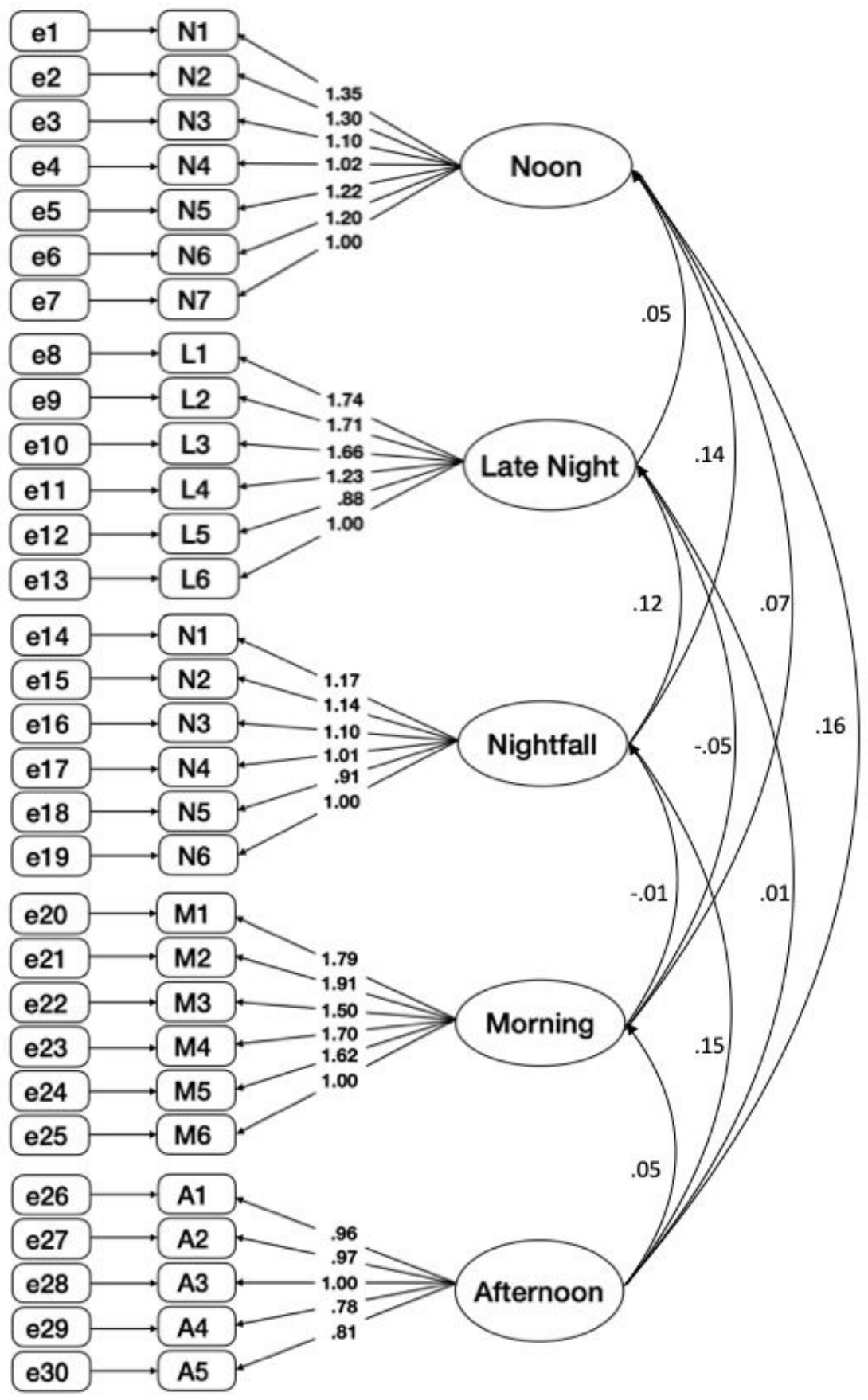

Figure 1

Standardized factor structures for a confirmatory factor analysis of a five-factor model. 